\title{
PRAIA DO PRESÍDIO: santuário da vilegiatura ${ }^{1}$
}

\author{
PRESÍDIO BEACH: sanctuary of the summering
}

\section{PLAYA DE PRESÍDIO: santuario de la vilegiatura}

\author{
Alexandre Queiroz Pereira \\ Professor do Instituto Federal do Ceará - Campus Quixadá \\ Doutorando no Programa de Pós-graduação em Geografia da UFC \\ Rua Frazão Cravo, 764, Lagoa - Quixadá - CE \\ CEP 63900000 \\ E-mail: aqp@ufc.bre aqp@ifce.edu.br
}

\section{Resumo}

A possibilidade de aproximação/construção de um objeto, neste estudo, segue a via da exploração da prática da vilegiatura marítima e seu caráter simbólico. A abordagem caracteriza-se pela tentativa de tecer uma trama. Neste sentido entende-se que o socioespacial é constituído por diversas dimensões da realidade (econômica, cultural, política e simbólica). Assim, faz-se necessário destacar três elos fundamentais deste escrito: um espaço (a praia), uma prática social (a estadia - a vilegiatura) e o conteúdo simbólico envolvido. No sentido de potencializar a análise foi selecionado o caso da praia do Presídio (Aquiraz-Ceará-Brasil), lugar simbólico, planejado para atender e fomentar a necessidade de estar à beira-mar. Aponta-se uma reflexão sobre a casa e a praia como espaços vivenciados, santuários primeiros, que envolvem a unidade familiar e a natureza. Neste caso, a prática da vilegiatura aparece como exemplo de construção desta interrelação entre espaços: a casa de praia e a praia.

Palavras-chave: espaço, maritimidade, casa de praia.

\begin{abstract}
The construction/approach possibility of an object follows the way of practical exploration of maritime summer vacation and its symbolic character. The approach is characterized by the attempt to weave a "tram", where socio-spacial is constituted from the diverse dimensions of reality (economic, cultural, symbolic and political). In such way, it becomes necessary to find three basic links to this writing: a space (the beach), a social practice (the staying - the summer house) and the symbolic content involved.

\footnotetext{
${ }^{1}$ Texto produzindo no bojo das leituras e discussões desenvolvidas na disciplina Dinâmicas dos Lugares Simbólicos: planejamento e imaginação, ministrada pelo Prof. Dr. Christian Dennys Oliveira.
} 
In the direction of increasing the analysis, the case Presídio Beach (Aquiraz-CearáBrazil) was selected, symbolic place, planned to attend and to foment the necessity of being by the sea. A reflection is pointed about the house and the beach as lived deeply spaces, first sanctuaries, that involve the familiar unit and the nature. In this case, summer house practice appears as an example of construction from this interrelation between spaces: the beach house and the beach.

Keywords: space, maritimity, beach house.

\section{Resumen}

La posibilidad de acercamiento/ construcción de un objeto sigue el camino de explotación de la práctica vilegiatura marítima y su carácter simbólico. El abordaje se caracteriza por el intento de cocer un trama, donde lo socioespacial es constituido a partir de diversas dimensiones de la realidad (económica, cultural, política y simbólica). Así, se hace necesario poner en relieve tres hilos fundamentales de este escrito: un espacio (la playa), una práctica social (la estada, la vilegiatura) y el contenido simbólico involucrado. En la búsqueda por potencializar el análisis, ha sido seleccionado el caso de la playa de Presídio (Aquiraz - Ceará - Brasil), lugar simbólico, planificado para atender y fomentar la necesidad de estar a la orilla del mar. Se ubica una reflexión sobre la casa y la playa como espacios donde hay vivencias, santuarios primeros, que incluyen la unidad familiar y la naturaleza. En este caso, la práctica de vilegiatura aparece como ejemplo de construcción de esta interrelación entre espacios: la casa de playa y la playa.

Palabras-clave: espacio, maritimidad, casa de playa

\section{Introdução}

Para este estudo verifica-se a realidade a partir de movimentos históricos e contemporâneos. Neste sentido, a possibilidade de aproximação/construção de um objeto segue a via da exploração da prática da vilegiatura marítima e seu caráter simbólico. A abordagem caracteriza-se pela tentativa de tecer uma trama, neste sentido entende-se que o socioespacial é constituído por diversas dimensões da realidade (econômica, cultural, política e simbólica). Assim, faz-se necessário destacar três elos fundamentais deste escrito: um espaço (a praia ${ }^{2}$ ), uma prática social (a estadia - a vilegiatura) e o conteúdo simbólico envolvido.

A praia, no Ocidente moderno, transformou-se simbolicamente. Sua paisagem, ao longo de aproximadamente três centúrias, foi artificializada para apropriação de sua natureza. A afirmação anterior parece uma eminente incoerência

\footnotetext{
${ }^{2}$ Pelo mundo, tal paisagem é um objeto de estudo de extrema atração científica.
} 
argumentativa, todavia, as práticas sociais de envolvimento ou redescobrimento do natural envolvem uma redefinição simbólica e material do meio. Corbin (1989), em seu trabalho clássico, define os percursos deste processo social, indicando como a literatura, a pintura, o discurso médico e até mesmo as novas interpretações dos textos bíblicos reconstituíram as imagens remetidas ao litoral. Ao raiar do século XXI, as praias e a sua natureza encontram-se "humanizadas", recobertas de imagens e práticas vinculadas ao prazer e ao redescobrimento do bem-viver.

Ainda no século XX, mais precisamente no seu último quartel, o acúmulo de estudos dirigidos pelas ciências da natureza (geografia física, geologia, ecologia, dentre outras) possibilitou o melhor conhecimento da dinâmica dos fenômenos naturais. Reconheceram-se, mais detalhadamente, os elementos e processos constituintes e transformadores do meio. Soube-se que muitos ecossistemas e geossistemas submetidos a intensas trocas de matéria e energia apresentam maior vulnerabilidade a intervenções sociais. As bordas litorâneas, com todas as suas faces, foram classificadas neste grupo. Assim, a faixa de praia, as dunas, os manguezais, as falésias são exemplos de feições dinâmicas, belas e que, mediante instrução científica, obrigatoriamente, devem ser protegidas contra "usos predatórios". O ambientalismo, enquanto discurso vinculado à proteção dos ecossistemas, fundamentada, dialeticamente, uma incontestável "unanimidade" moderna: é privilégio apropriar-se particularmente destas paisagens de exceção.

Internacionalmente, morar a beira mar significa (e simboliza) privilégio social. Reconhece-se a permanência e a importante de outros usos ${ }^{3}$. No entanto, a moradia/estadia representa uma síntese das possibilidades de satisfação das "necessidades" essenciais e/ou fugazes. Nas metrópoles litorâneas as orlas marítimas estão predominantemente ocupadas por arranha-céus. São vários imóveis de propriedade de estratos sociais potencialmente integrados ao consumo de mercadorias de restrito acesso, pois alcançam elevados preços. A título de exemplo, em 2007, o metro quadrado de imóveis em terrenos praianos pode ser adquirido pela bagatela de $\mathrm{R} \$$ 7.800,00 em Malta, $\mathrm{R} \$$ 6.500,00 na Espanha e no Brasil, em média, por $\mathrm{R} \$ 3.583,00$ (EMBRATUR/FGV, 2007). Esses preços representam a aceitação da relativa raridade (lei da escassez) constituída a partir das condições naturais, mas, sobretudo, pela força

\footnotetext{
${ }^{3}$ Tais usos podem ser listados: portuário, defesa territorial, locação de plantas industriais, lócus de
} 
simbólica representada por estas paragens litorâneas. Os dados referentes ao mercado de imóveis indicam uma das facetas (econômicas) relacionadas à paisagem litorânea.

A aproximação da sociedade européia com os efeitos da maritimidade propiciou uma sorte de novas práticas sociais. Dentre elas a estadia temporária, a vilegiatura, anterior a toda denominação que conhecemos atualmente como turismo, criou uma aura simbólica capaz de transformar a paisagem litorânea em "santuário natural" do lazer e da diferenciação social pró-elistismo. Boyer (2008) cita os exemplos pioneiros das estâncias balneárias (como Biarritz e Monte-Carlo), caracterizando-as como espaços onde a vilegiatura serviu, dentre outros aspectos, como espaço econômico e cultural demarcando por relações aristocráticas com finalidade de construir um espaço para o lazer, hermético às camadas desfavorecidas. Eram lugares com destacáveis características naturais e onde se gestavam costumes tidos como sofisticados e que sensivelmente eram disseminados como modelares as diversas camadas sociais.

Tais práticas espalham-se pelo mundo ao longo do século XIX e apresentam-se como dominantes no século XX e início do século XXI. A vilegiatura, o turismo e o litoral foram absorvidos positivamente pelo imaginário das "populações" urbanas de todo o Novo Mundo (assim como de todo o resto). Todavia, de acordo com Dantas (2004) esta assimilação não se dá como transposição total. Destaca-se uma dialética entre o tradicional e o novo, entre o interno e o externo, entre o litoral e o sertão, entre as práticas marítimas tracionais e as modernas (com filiação européia). O modo de vida urbana avança pelo espaço mundial (Lefebvre, 1999) e a ele estão imbricadas as ditas práticas marítimas modernas. A vilegiatura marítima espalha-se nos trópicos reforçando a idéia de conquista do "paraíso" das águas mornas e do sol abundante. Tal imagem consolida-se principalmente com a necessidade, planejada ou não, dos estados nacionais de elaborarem políticas de turistificação ${ }^{4}$ dos lugares.

No sentido de potencializar a análise foi selecionado o caso da praia do Presídio (Aquiraz-Ceará-Brasil), lugar simbólico, planejado para atender e fomentar a necessidade de estar à beira-mar. Em um primeiro momento, aponta-se uma reflexão sobre a casa e a praia como espaços vivenciados, santuários primeiros, que envolvem a

\footnotetext{
realização de extrativismo, agricultura e pecuária.

${ }^{4}$ Não entraremos, neste artigo, na discussão e na tentativa de diferenciar e/ou conceituar paralelamente as práticas de vilegiatura e turismo. Contudo, colocamo-nos da perspectiva contrária daqueles que convém considerar a vilegiatura enquanto um "turismo de (em) segunda residência".
} 
unidade familiar e a natureza. Neste caso, a prática da vilegiatura aparece como exemplo de construção desta interrelação entre espaços: a casa de praia e a praia.

\section{A vilegiatura e as relações na casa de(na) praia}

As práticas sociais relacionadas ao viver e ao habitar podem ser definidas como àquelas que produzem significado e ligação do homem como o espaço. Nestes termos, a casa agrega papéis sociológicos, espaciais e simbólicos, e lembrando Bollnow (2008), pode-se afirmar que a casa é um território central de todas as relações espaciais.

Todavia, na moderna arquitetura do século XX a casa é transformada em máquina de morar. Desta forma, a casa, a (primeira) residência, ganha ares de cotidianidade $^{5}$, repetição e monotonia (Lefebvre, 1991). A residência é conduzida como espaço da satisfação das primeiras necessidades (comer e dormir), ou melhor, um ponto de apoio para o local de trabalho. Para o lazer, para a fuga do cotidiano, para realização humana associada ao ócio diz-se ser necessário estar em outro lugar, ou seja, é necessário fragmentar o espaço e o tempo. Apesar de a casa representar um santuário da vida familiar, para os abastados estar todos os dias em uma única casa torna-se insuportável.

No século XX propaga-se uma vontade. A posse de uma residência não habitual, de uso ocasional, surge como uma possibilidade de "renovar" as forças desgastadas pela rotina estafante nos centros urbanos. Assim, a vilegiatura é introduzida como caminho "ideal" em direção ao tão desejado retorno a natureza. No entanto, a discussão não pode ser simplificada pelos argumentos dualistas: residência-segunda residência; trabalho-ócio; cidade-natureza; rotina-diferença. Todos os pares direcionam para noções como mudança brusca e/ou fuga. Todavia, tais mudanças não implicam rupturas por completo, à medida que os tempos e os espaços se integram numa unidade: o modo de vida. Dialeticamente, o modo de vida condiciona a maneira pela qual os segmentos sociais concebem e definem seu espaço-tempo dependendo do estado que ocupem. Para o presente estudo, conceitua-se a vilegiatura como uma prática gestada no modo de vida urbano.

\footnotetext{
${ }^{5}$ Lefebvre (1991) indica a separação 'homem-natureza' e a ascensão da nostalgia em função de uma natureza perdida como resultados da constituição da cotidianidade. Consultar p. 46.
} 
Vamos à praia: é necessário vilegiar! Imagine a seguinte situação: "Fortaleza (CearáBrasil), quarta-feira antecedente a quinta-feira da Semana Santa, são aproximadamente 20 horas e 30 minutos, famílias residentes nos bairros do Papicu e Praia de Iracema organizam alguns pertences e os colocam dentro do porta-malas do carro. Jantam e tomam a estrada em direção a sua casa de praia. Nesta noite, o trânsito já é intenso nas rodovias que levam em direção as praias cearenses. São milhares de famílias e seus automóveis. Elas vão à praia e lá estarão por pelo menos três dias. O que farão? Cada uma tem seus objetivos. E cada familiar tem seus anseios: a mãe (funcionária pública) vai organizar um almoço para reunir os amigos e parentes, o pai (professor universitário) escreverá um artigo científico, e o filho (surfista) vai 'pegar onda"”.

Com uma série de variações, essa descrição exemplifica uma condição real, transcorrida inúmeras vezes ao longo do ano, em diversas cidades litorâneas ou próximas ao litoral. Simbolicamente podemos, lembrando o estudo de DaMatta (1991), estabelecer um novo roteiro compreendido pela relação entre a casa de praia e a praia.

Tal binômio nos leva a refletir acerca da fragmentação do tempo-espaço social. A praia é o lugar selecionado. Artistas louvam a praia e as práticas que a estadia permite. Lembremos a famosa letra da música Tarde em Itapoã composta por Vinicius De Moraes e Toquinho.

Um velho calção de banho

O dia pra vadiar

É bom

Um mar que não tem tamanho

Passar uma tarde em Itapuã

E um arco-íris no ar

Ao sol que arde em Itapuã

Depois na praça Caymmi

Ouvindo o mar de Itapuã

Sentir preguiça no corpo

Falar de amor em Itapuã

E numa esteira de vime

Beber uma água de coco

Depois sentir o arrepio

É bom

Passar uma tarde em Itapuã

Ao sol que arde em Itapuã

Ouvindo o mar de Itapuã

Falar de amor em Itapuã

Do vento que a noite traz

E o diz-que-diz-que macio

Que brota dos coqueirais

E nos espaços serenos

Sem ontem nem amanhã

Dormir nos braços morenos

Da lua de Itapuã

Enquanto o mar inaugura

Um verde novinho em folha

É bom

Argumentar com doçura

Passar uma tarde em Itapuã

Com uma cachaça de rolha

Ao sol que arde em Itapuã

E com o olhar esquecido

Ouvindo o mar de Itapuã

No encontro de céu e mar

Falar de amor em Itapuã

Bem devagar ir sentindo

A terra toda a rodar 
Várias Itapuã's existem por todo o País. Praias e mais praias são transformadas em santuários naturais. Pensando a casa na praia, do que difere da moradia habitual? Permite novas relações dissociadas do cotidiano? É certo que atualmente não se trata da vilegiatura dos "italianos" renascentistas ou dos aristocratas e/ou burgueses do século XVIII e XIX. No entanto, a vilegiatura realizada nos trópicos (brasileiros) atualmente conduz elementos "genéticos" dos processos históricos e dialéticos de sua formação.

No início do século XXI, no Nordeste brasileiro a casa ${ }^{6}$ de vilegiatura marítima consolida-se a tal ponto que predomina. Assim, vilegiatura, no nordeste brasileiro, é sinônimo de casa de praia. Historicamente, percebe-se que o tecido urbano das principais regiões metropolitanas nordestinas (situadas todos no espaço litorâneo) tem ampla contribuição das ocupações de "veraneio" datadas, principalmente, a partir do segundo pós-guerra mundial. A quantidade de aglomerados de segundas residências no litoral nordestino faz intuir o sucesso que tal prática alcançou nas classes solváveis locais.

Neste sentido, elencamos o vilegiaturista "moderno" como sujeito detonador de uma trama de relações sociais. Esta trama é tecida a partir de um ponto, a casa de vilegiatura, um espaço microssocial, um complexo onde não se pode definir simplesmente pelo uso em favor do lazer, à medida que se torna cada vez mais difícil estabelecer os limites entre os tempos da vida cotidiana (livre e trabalho). Todavia permanece a impressão de que a casa, seja segunda ou primeira, representa a fartura, o aconchego, o encontro e a proteção. São condições "sagradas" da existência do núcleo familiar transpostas para o contexto do domicílio de uso ocasional. Apresenta-se uma hipótese: a casa de praia, longe de representar uma fuga do cotidiano, configura-se como extensão das relações estabelecidas na "casa habitual". Extensão que não representa uma mera repetição, à medida que, a vilegiatura se constitui a partir de relações de negação, complementaridade e interpenetração.

As casas, todavia, estão situados num espaço mais amplo: a praia. Ao mencionar este espaço, primeiramente são lembradas suas formas naturais (geomorfológicas e paisagísticas). O mar, as dunas, a faixa de praia, os manguezais, as

\footnotetext{
${ }^{6}$ Quando nos referimos a casa estamos genericamente tratando do ambiente e não especificamente das formas arquitetônicas. Lembramos isso por que a habitação de vilegiatura pode apresentar-se em diferentes formas, como, por exemplo, apartamentos.
} 
restingas e as falésias são patrimônios naturais e, é, socialmente, reconhecido que é um privilégio estar próximo destes ambientes. Enquanto, legalmente estas paragens e suas formas são patrimônio de todos, incluindo ai a legislação ambiental que regulariza e restringe o acesso. Todavia, tal legislação e seus mecanismos reforçam a noção de raridade.

As características ecossistêmicas das paragens litorâneas, também, são incorporadas pelo discurso médico-científico que reforça as benesses compreendidas pelo fato de morar e/ou do estar ao ar livre frente ao mar. Assim, as casas são construídas entre estas formas naturais, possibilitando a saúde, o descanso, a visibilidade, o contato, a posse, e até mesmo, a exclusividade.

Os agentes promotores do mercado imobiliário se utilizam destas imagens. Incorporadoras (e construtoras) perceberam o movimento, anteriormente, espontâneo, e conduziram suas estratégias de vendas (criação de sonhos) para velhos e novos produtos: as casas individuais, os condomínios, os resorts e condo-resorts. Em todos os casos, a praia constitui o espaço concebido a ser conquistado pelo planejamento e pela imaginação.

Dois universos simbólicos interrelacionados. Metaforicamente, a praia e a casa são santuários onde o sagrado é representado pela propriedade e as condições que ela sugere. Profanar essas condições significa impedir que a "harmonia" das relações se constitua de fato. Num discurso hipotético o vilegiaturistas diz: ...a praia é linda a brisa é suave e o por do sol nos faz meditar sobre todos a nossa vida... E melhor, tudo isso é meu. Eu posso estar neste 'paraíso' quando quiser.

\section{Praia do Presídio: refúgio de vilegiaturistas}

A praia do Presídio - localizada no município de Aquiraz, estado do Ceará, Brasil - dista cerca de $50 \mathrm{~km}$ da capital cearense. As vias que direcionam a praia são as rodovias estaduais CE-040 e CE-453. A primeira tem seu quilometro zero localizado em Fortaleza e prolonga-se pelos municípios do litoral leste cearense. A segunda é curta. Com 9 km de extensão, conecta a CE-040 as praias do distrito de Jacaúna - Aquiraz.

Os limites da praia são demarcados a leste pelo manguezal do rio do Iguape; a oeste pelo empreendimento turístico-imobiliário Aquiraz Riviera, e ao sul por um 
cordão de dunas fixas que recobrem os tabuleiros pré-litorâneos (figura 01). A toponímia originou-se de uma função história desta praia. Ao longo dos séculos XVII e XVIII alguns degredados foram aprisionados neste lugar antes de serem transportados para o Velho Continente.

No tangente a configuração territorial ${ }^{7}$ contemporânea da praia, destacam-se o manguezal, a foz do rio do Iguape e as dunas fixas e semifixas associados à faixa de praia. No chamado pós-praia está construído o loteamento, com as vias dispostas paralela e perpendicularmente ao Oceano Atlântico. As primeiras residências de uso ocasional foram construídas na praia no início dos anos 1980, a partir da compra de lotes da família Studart, proprietária de 157 hectares de praia. De acordo com as informações da Prefeitura Municipal, atualmente, perto de 700 imóveis constituem esta praia.

Os poucos moradores, cerca de 50 famílias, não são nativos, mas originárias de praias próximas. Estes ocupam duas áreas bem restritas e nítidas. A primeira área corresponde ao trecho inicial da via principal do loteamento, com os quintais situados no manguezal. A segunda encontra-se numa área marginal, mais precisamente, no sopé da duna fixa que delimita o empreendimento imobiliário.

\footnotetext{
${ }^{7}$ No dizer de Santos $(2008$, p. 84) a configuração territorial é "formada pela constelação de recursos naturais, lagos, rios, planícies, montanhas e florestas e também de recursos criados: estrada de ferro e de rodagem, condutos de toda a ordem, barragens, açudes, cidades, o que for".
} 


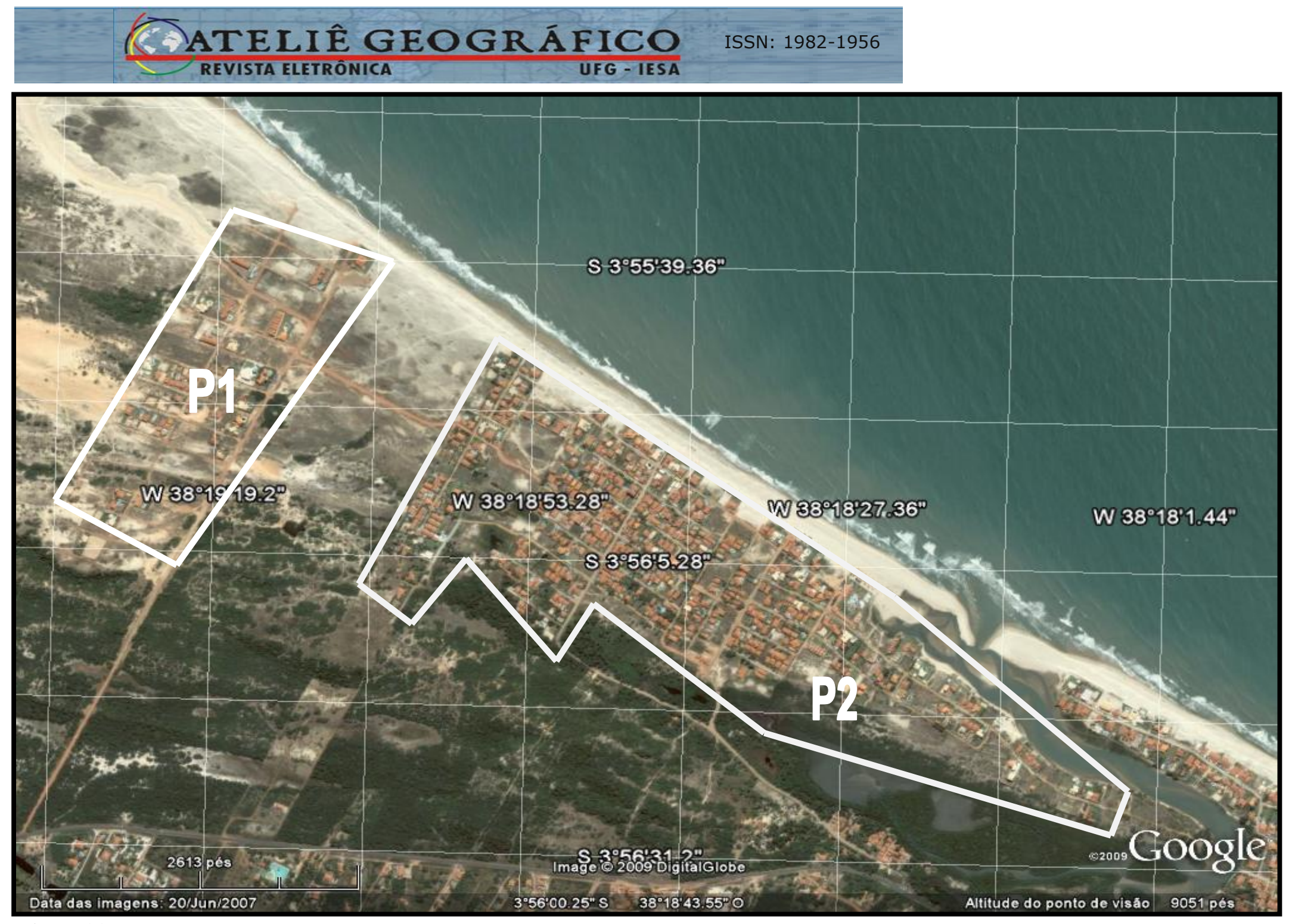

Figura 01. Vista espacial da praia do Presídio

Fonte: Google Earth 
As residências individuais de uso ocasional (segundas residências) são os elementos predominantes na paisagem. As plantas e formatos não são homogêneos. As casas estão fundamentadas em plantas arrojadas (figura 02), com grande índice de área construída, como também em tipologias mais simples. Entre as ruas de terra batida ${ }^{8}$, também estão presentes na paisagem equipamentos hoteleiros, pousadas e condomínios horizontais. Na praia não existem grandes centros comerciais. Apenas dois pequenos mercados abastecem os caseiros e vilegiaturistas com mercadorias alimentícias e de primeira necessidade. Existem ainda uma escola pública de ensino fundamental e um centro comunitário. Este último serviu por alguns meses como base de realização de cursos de línguas estrangeiras promovidas por uma organização não-governamental americana. No momento, o espaço não registra atividades programadas ou periódicas.

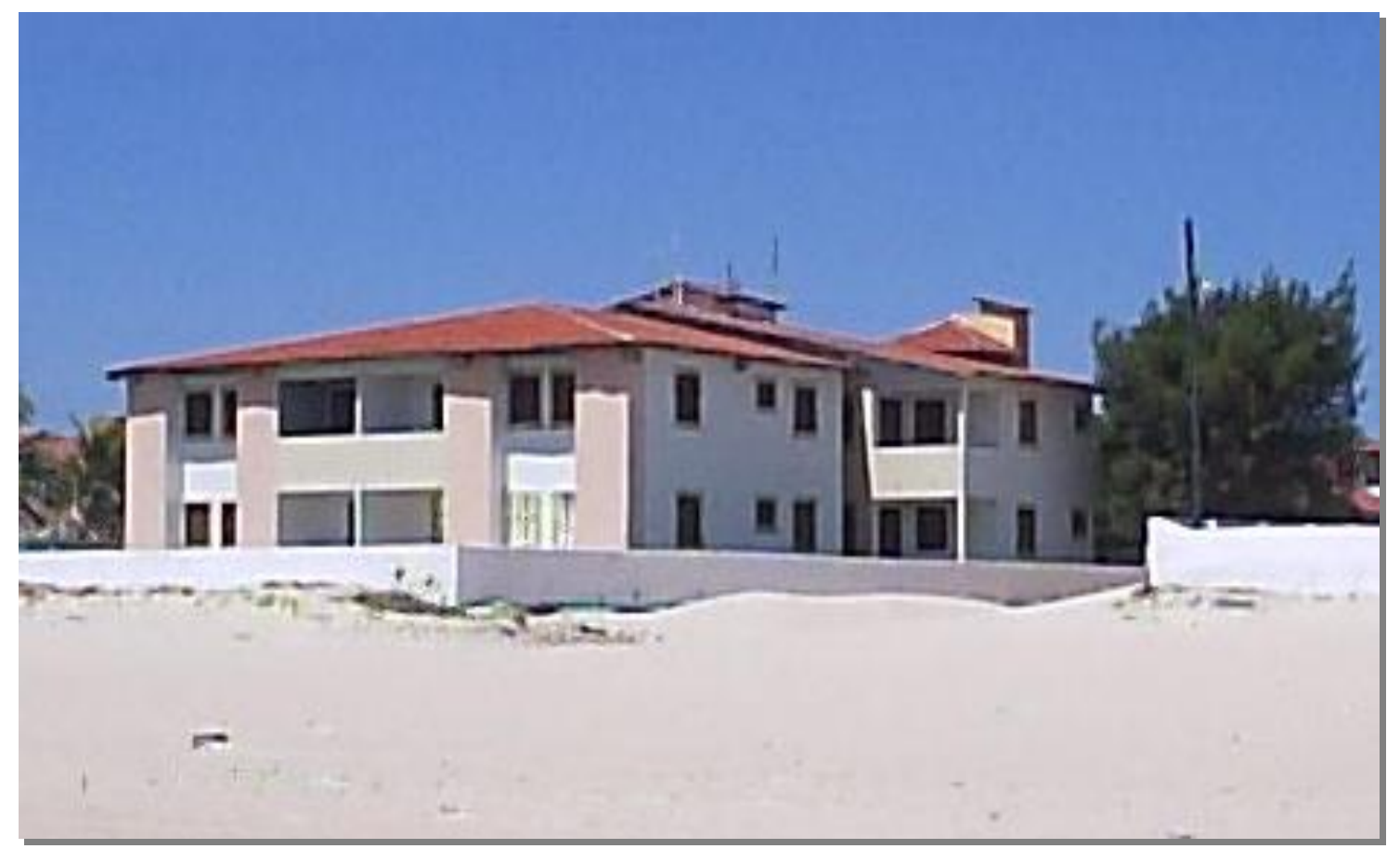

Figura 02. Casas de veraneio com dois pavimentos

Autor: Alexandre Q. Pereira, 2009.

Em Presídio duas ocupações foram constituídas: a $P 1$ e a $P 2$. Em conjunto com os espaços da praia do Porto das Dunas (também em Aquiraz), a ocupação P2, em

\footnotetext{
${ }^{8}$ Apenas a rua principal da Praia do Presídio é recoberta por pedra tosca. Com relação às infraestruturas básicas, inexiste sistema de abastecimento público de água e, como também, o sistema de coleta pública de esgotos.
} 
Presídio, corresponde à maior concentração de segundas residências em Aquiraz. O mercado imobiliário é um mediador das transformações desenvolvidas nas ocupações. Várias placas anunciam a possibilidade de venda e de locação dos imóveis. Uma delas apresenta um slogan que chama a atenção: além do lazer, um investimento. O letreiro atrai os clientes, confortando-os econômica e racionalmente, à medida que adquirem um paraíso para o divertimento e também uma mercadoria de expressiva rentabilidade.

A ocupação P1 é a mais recente de todo o Aquiraz. Sua ocupação reúne características do vilegiaturistas dos anos 2000, ou seja, a construção de condomínios fechados. Esta ocupação apresenta via de acesso própria, que proporciona independência com relação às outras ocupações. A tendência ao isolamento, condicionada pelos elevados preços dos lotes e também pelas grandes construções contemporâneas, permanece nesta área de expansão da praia do Presídio. Os condomínios e casas isoladas evidenciam a presença de veranistas que não desejam contatos, ou seja, temem que outros sujeitos possam minimizar ou contrariar o usufruto da tranqüilidade e da praia.

A praia ganhou notoriedade na mídia. A partir do título "Praia do Presídio é refúgio de veranistas", a reportagem do jornal Diário do Nordeste, de 12 de julho de 1998, objetiva alcançar a identidade do lugar. A matéria jornalística enfatiza o fato de que a ocupação "nasceu" com a finalidade de torna-se um aglomerado homogêneo de vilegiatura, e destaca o sucesso do planejamento dos empreendedores. De fato, por todos os ângulos: quem está à beira mar na Praia do Presídio olha em direção ao continente não consegue vislumbrar outra paisagem predominante, senão, o aglomerado de casas para a vilegiatura (figura 03). 

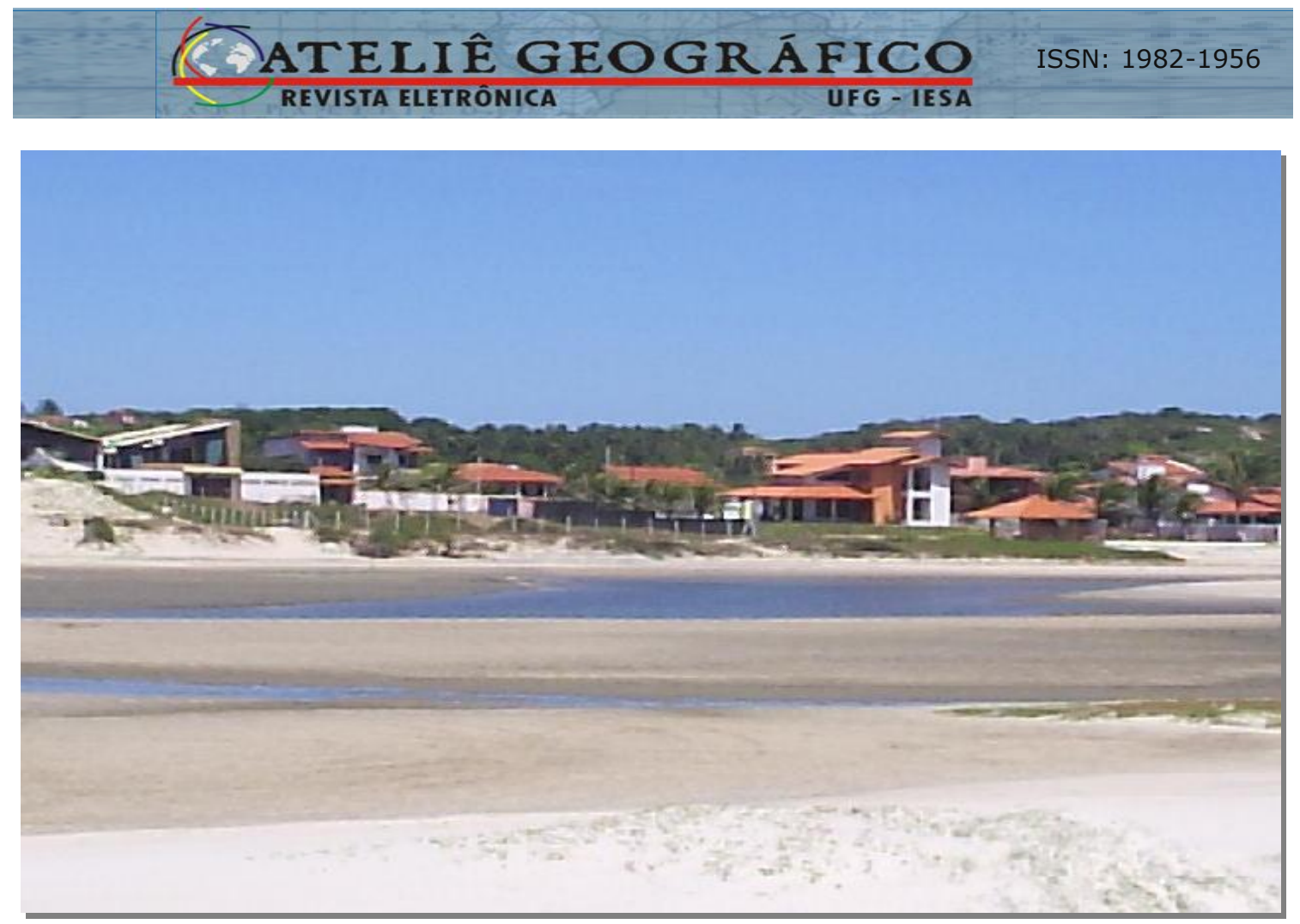

Figura 03. A “muralha quer cerca o mar" na Praia do Presídio Autor: Alexandre Q. Pereira, 2009.

Inúmeros acontecimentos reafirmam a relação simbólica entre a praia e a vilegiatura. Nos primórdios das construções, em virtude da inexistência de uma legislação municipal própria de uso e ocupação do solo, os vilegiaturistas, à época, seguiram normas ditadas pelo empreendedor imobiliário, Luiz Studart Junior, bisneto de Oswaldo Guilherme Studart, principal proprietário dos seis quilômetros da área.

Dentre estas normas, são destaques: a não-construção de casas de mais de dois pavimentos, a proibição da entrada de ônibus de excursão, os chamados "farofeiros", assim como não é permitida a construção de barracas na zona de praia. Para os vilegiaturistas, o Presídio é uma "praia particular". É observável o esforço em proporcionar aos vilegiaturistas, "verdadeiros donas da praia", um espaço harmônico e livre de conflitos com outros sujeitos demandadores das benesses deste lugar.

Outro fato que destaca a coesão dos vilegiaturistas em Presídio é o caso da presença de uma segunda residência de propriedade de uma congregação de padres, na qual, aos sábados, são celebradas missas freqüentadas exclusivamente pelos fortalezenses. Esse espaço é um dos pontos de encontro dos vilegiaturistas católicos. Percebe-se com isso que na organização do tempo de ócio, são destinados momentos para as práticas religiosas e de agradecimento a divindade. 
Todavia, a tensão também é presente. Os vilegiaturistas, com o intuito de promover um carnaval de praia ordenado e com um público selecionado, organizaram blocos de foliões que desfilariam durante as tardes dos dias do feriado carnavalesco. A festa alcançou um sucesso inesperado e atraiu dezenas de milhares de pessoas que tomaram as ruas e provocaram um "caos" indesejado. Com isso, as brincadeiras, as músicas e agitação foram restritas e passaram a seguir regras por determinadas pelos vilegiaturistas. Até mesmo o Poder municipal, cedendo às influências exercidas pelos mesmos, determinou, no carnaval de 2004, toque de silêncio a partir das vinte e três horas.

O empreendedor e os vilegiaturistas exercem um campo de forças capaz de reafirmar seus interesses. A "praia não é compartilhada" com sujeitos sociais incapazes de seguir o mesmo padrão de vida. A exceção é feita à medida que outros sujeitos servem aos seus interesses, sendo contratados como caseiros e/ou vigias. A matéria do jornal O Povo (Fortaleza-CE) exemplifica a imagem que se tem da Praia do Presídio. Aparentemente, o texto deixa transparecer que os usos e as funções atuais correspondem à vocação natural da praia.

Veranear na Praia do Presídio faz parte do estilo de vida requintado de um discreto e seleto grupo, que prioriza o descanso e o relaxamento.

Estilo que, se não pode ser adotado pela maioria da população, pode ser acompanhado bem de perto, por quem com ele se identifica. (PRAIA DO..., 1998, p.16).

Em relação à exclusividade, o trecho jornalístico acima lembra descrição elaborada por Corbin (1986).

O que precede deixa entrever a significação e as modalidades sociais da propagação da vilegiatura marítima. Esta constitui um conjunto de práticas inicialmente reduzidas às esferas concêntricas compostas pela família real, a alta nobreza, os talentos ou as personalidades da moda e a gentry. (Op. Cit, p. 286-287).

Na contemporaneidade, situação que não se pode ignorar são os múltiplos desejos e finalidades direcionadas à praia e à vilegiatura. Urbain (1996, apud DANTAS, 2002) pensou numa classificação dos vilegiaturistas a partir de suas relações de sociabilidade estabelecida com os moradores. São destacadas três classes para a taxonomia dos vilegiaturistas: de refúgio, de coabitação e popular. Pensando no 
enquadramento, o caso estudado se associaria predominantemente ao primeiro tipo, à medida que o histórico de ocupação e os fatos derivados da pesquisa de campo demonstram o desejo pelo estabelecimento contínuo de barreiras simbólicas, econômicas e sociais.

A escolha pelo isolamento demonstra que a relação vilegiaturista-casa-praia não está dissociada das neuroses e dos medos. Não são os medos dos monstros marinhos e das fossas abissais destacados por Corbin. Comuns nas grandes aglomerações urbanas, as cercas elétricas, os muros altos e os seguranças particulares são itens com presença acentuada na praia do Presídio. Para os vilegiaturistas, a violência, representada por assaltos, roubos e invasões, é uma inimiga a ser eliminada através da vigilância, desconfiança e do recolhimento. Ao descrever, percebe-se que a vilegiatura marítima contemporânea condiciona contraditoriamente expansão e retração das relações de sociabilidade.

$\mathrm{Na}$ elaboração desta sociabilidade são conformadas mediações com elementos naturais do meio com a própria casa de praia. A arquitetura das casas capta para o seu interior as amenidades dos símbolos naturais da praia.

\section{Os significados da natureza da praia para os vilegiaturistas em Presídio}

Os especialistas em geomorfologia afirmam que a planície litorânea é um complexo de formas muito vulneráveis. As ocupações nestes espaços tendem a provocar erosão, desmatamentos, deposição de resíduos sólidos, deposição de esgoto "in natura" e retirada de terra. Por outro lado, os vilegiaturistas reconhecem neste espaço possibilidade de aproximação do que é natural e saudável. Contudo as formas naturais são incorporadas às práticas da estadia de maneiras distintas.

A visão sistêmica dos cientistas não alcança o imaginário dos vilegiaturistas. As dunas e o manguezal ${ }^{9}$ aparecem apenas como entraves ao avanço de suas construções. As práticas de lazer desenvolvidas por estes excluem tais ambientes. A vilegiatura não inclui necessariamente os preceitos da preservação ambiental. A título

\footnotetext{
${ }^{9}$ O manguezal do conjunto Iguape-Presídio é utilizado por outros sujeitos (moradores ou visitantes de comunidades próximas) que lá realizam a atividade pesqueira e piqueniques. Estes visitantes aproveitam os frutos do mar extraídos do próprio lugar para prepararem suas refeições, acompanhadas geralmente por bebidas alcoólicas. Popularmente, esta prática é conhecida como "fazer uma cabana".
} 
de exemplo, muitas lagoas interdunares, fundamentais para o abastecimento do lençol freático, foram aterradas para a construção de vários imóveis. Além disso, os esgotos domésticos são lançados em fossas sépticas altamente poluidoras das fontes hídricas. Muitos trechos da planície flúvio-marinha (manguezal) foram desmatados e plantas de jardinagem substituem a vegetação do complexo litorâneo.

A interpretação da natureza da praia pelos vilegiaturistas está vinculada aos "recursos renováveis". Na teia simbólica destacam-se o mar, o sol e a brisa. São estes elementos que representam além de um fluxo de energia dos processos naturais, uma carga energética e simbólica que vai ao encontro dos anseios destes sujeitos sociais.

O mar, com sua força e gigantismo, lava e refresca. Suas ondas demonstram a grandiosidade das relações cíclicas da natureza, levando a comparações com a dinâmica da vida social: depois da tempestade, a bonança. O mar tira todos os males. Para o vilegiaturista, o banho nas águas mornas do Atlântico do Sul energiza, cura e renova. Durante as caminhadas matinais ou vespertinas o horizonte fintado pelo olhar reforça a necessidade de contemplação, tornando necessário repensar a vida ou ligá-la a outros rumos. A escritora cearense Rachel de Queiroz, pensando o seu estado, interpretou a figura do mar e assim o descreveu:

\footnotetext{
Mar verde, bravio, porém leal. Não tem profundezas súbitas, não tem correntes enganosas, não tem 'bocas' nem vórtices perigosos. Está ele todo ali, na superfície, bem à vista para quem quiser conhecer e amar. As ondas são grandes, às vezes paredões d'água, que, ao se erguem, formam um sulco profundo à retaguarda, param no alto um instante e só então quebram a crista em espumas; mas aí vêm de manso, ritmadas, avançando lentas até a cama de areia. (QUEIROZ \& QUEIROZ, 1996, p. 26, grifo nosso).
}

O sol é sinônimo de vitalidade, seus raios tocam os corpos lapidando-os. O astro rei doura a pele a serviço de um dominante padrão de beleza. A aurora representa o início de um novo ciclo, enquanto o crepúsculo tinge o céu, dando aos vilegiaturistas a oportunidade de capturar imagens singulares. A visualização da paisagem que se forma é um privilégio da estadia.

A brisa representa a síntese promovida pela interação constante entre a superfície (terrestre e marinha) e a energia solar. Ela adentra o ambiente e acalenta a sensação térmica, dando ao vilegiaturista conforto e tranquilidade. Em conjunto, mar, sol e brisa conformam, em termos naturais, os sons, os cheiros e as demais sensações emanadas pela paisagem marítima. 


\section{A casa de praia por dentro e as temporalidades na praia}

Em trabalho anterior (PEREIRA, 2006), foi introduzida uma descrição e uma interpretação breves dos significados dos principais componentes internos das casas de praia cearense. Na ocasião, evidenciaram-se como itens frequentes o muro, a garagem, os alpendres, a piscina, a churrasqueira e a casa ou dormitório do caseiro ${ }^{10}$.

Tal compartimentação do ambiente indica as atividades desempenhadas na casa de praia. De elementos de função banal como a garagem aos de uso voltado diretamente ao lazer como a piscina. A presença desta demonstra o desejo de restrição, à medida que mesmo tendo o mar ao lado, constrói-se para ocasiões onde a praia está cheia de outros banhistas. A churrasqueira, geralmente próxima a piscina, é estratégica para a realização das festas, das confraternizações e das comilanças. Os alpendres, abertos a brisa, servem como sala de estar e também como dormitório. Neste ambiente, o relaxamento é conduzido pela permanência numa rede de dormir.

O muro e a casa ou dormitório do caseiro estão vinculados a manutenção da ordem e da preservação da propriedade. O muro separa os de dentro dos de fora, os proprietários dos estranhos. Demarca a área na qual o vilegiaturista exerce o direito constitucional da propriedade privada. A casa ou dormitório do caseiro assegura a vigilância e o cuidado com a manutenção e limpeza do ambiente. $\mathrm{O}$ caseiro representa $\mathrm{o}$ dono, estando presente inclusive nos momentos de sua ausência.

Quando chegam os finais de semana, os feriados "prolongados" e as férias (ou mesmo quando estes se dão simultaneamente) os carros circulam e as casas são novamente ocupadas. Pela manhã, alguns vilegiaturistas caminham pela praia, outros acordam já próximo da "hora" do almoço. Entre a virada do período matutino e a chegada da tarde, outros vão ao mar e por algumas horas complementam o banho de sol ao banho de mar. Ao fim da tarde, as caminhas são novamente praticadas e o pôr do sol pode ser avistado da beira-mar ou do alpendre. À noite, a casa é o aconchego e o sono é embalado pelo vento que desbrava e traz aos ouvidos os sons do mar.

\footnotetext{
${ }^{10}$ Não são todas as segundas residências a apresentarem os seis itens. Geralmente, quanto mais abastado é o seu proprietário, mais itens a compõem.
} 
O vilegiaturista se vê "feliz". Está onde muitos queriam e não podem. Em um momento, ele se entedia, entra em seu automóvel e volta ao seu habitat ${ }^{11}$ : a casa, a rua, o trânsito, o trabalho, em geral, a cidade. Contudo, a casa de praia e a praia estão lá, no mesmo lugar, em uma natureza urbanizada a sua disposição.

\section{Considerações finais}

Restam-nos pensar no que consiste a vilegiatura e os espaços litorâneos para as relações simbólicas na sociedade contemporânea. Uma primeira avaliação, talvez apologética e romântica, indica que o vilegiaturista usa a casa e a praia na tentativa de ampliar sua vida cotidiana, estabelecendo momentos diferenciados. Ele usa a arquitetura da casa e o marítimo como espaços outros, vivenciados temporariamente. Todavia, uma temporariedade repetida e inclusa no tecido social de suas atividades e (pseudo)necessidades, primordialmente, àquelas referentes ao lazer e ao descanso. Uma segunda análise conduz a constatação da situação de empobrecimento das relações. Neste sentido, as muitas praias no litoral nordestino e, no caso específico da praia do Presídio, constituem um kistch, imitação barata e de mau gosto, se comparadas as villas de otium romanas, quando os subúrbios eram produzidos como arte. (AMBROZIO, 2005). Diferente de uma visão linear que aponta para uma conclusão, dialeticamente defende-se que a vilegiatura marítima confronta o uso ao consumo, e desta forma, configura-se como representação da complexidade social derivada, e ao mesmo tempo, produtora do processo de criação das diferenças.

$\mathrm{Na}$ praia do Presídio as relações sociais proporcionadas pela vilegiatura marítima multiplicam-se e tornam-se fugidias às aproximações objetivas. A praia e a casa são materialidades re-imaginadas pelo (ou sem) planejamento.

\section{Referências Bibliográficas}

AMBRÓZIO, Júlio. Viagem, turismo, vilegiatura. GEOUSP - Espaço e tempo. São Paulo, no 18, 2005. pp. 105-113.

\footnotetext{
${ }^{11}$ Remetemos este conceito ao entendimento construído por Henri Lefebvre. Ver especialmente o livro $A$ Revolução Urbana (1970).
} 
EMBRATUR (BRASIL). Mercado de Turistas Estrangeiros de Segunda Residência no Brasil. Brasilia, 2007. Disponível em <www.turismo.gov.br/dadosefatos>.

Acessado em 12 jan 2009.

BOLLNOW, O. F. O homem e o espaço. Tradução de Aloísio Leoni Schmid. Curitiba: Editora UFPR, 2008.

CLAUDINO SALES, V. C de. Os litorais cearenses. In: SILVA, J .B. et al. (orgs).

Ceará: um novo olhar geográfico. Fortaleza: Edições Demócrito Rocha, 2007. p. 231 260.

CORBIN, Alain. O território do vazio. A praia e o imaginário ocidental. Tradução de Paulo Neves. São Paulo: Companhia das Letras, 1989.

DAMATTA, R. A casa \& a rua: espaço, cidadania, mulher e morte no Brasil. $4^{\text {a }}$ Ed. Rio de Janeiro: Guanabara Koogan, 1991.

DANTAS, E.W.C. O mar e o marítimo nos trópicos. GEOUSP. Espaço e tempo, São Paulo, no 15, p. 63-76, 2004.

. Mar à Vista: estudo da maritimidade em Fortaleza: Fortaleza: Museu do Ceará, Secretaria de Cultura e Desporto, 2002.

LEFEVBRE, Henri. A revolução urbana. Tradução de Sérgio Martins. Belo Horizonte: EdUFMG, 1999.

A vida cotidiana no mundo moderno. Tradução de Alcides João de Barro.

São Paulo: Ática, 1991.

PEREIRA, A. P. Urbanização e veraneio marítimo no Ceará. In: SILVA, J. B.;

DANTAS, E. W. C.; ZANELLA, M. E.; MEIRELES, A. J. A. (orgs). Litoral e sertão, natureza e sociedade no nordeste brasileiro. Fortaleza: Expressão Gráfica, 2006. p. $307-316$.

PRAIA DO Presídio é refúgio de veranistas. Diário do Nordeste. Fortaleza, 12 jul. 1998. Cidade, p. 16.

QUEIROZ, Rachel de; QUEIROZ, M. L. de. O nosso Ceará. Fortaleza: Fundação Demócrito Rocha, 1996.

SANTOS, M. Metamorfoses do espaço habitado. $6^{\text {a }}$ ed. São Paulo: EdUSP, 2008.

Recebido para publicação em julho de 2009

Aprovado para publicação em dezembro de 2009 